\title{
Produção de mudas de alface com biofertilizantes e substratos
}

\author{
Damiana Cleuma de Medeiros; Bruno Afonso Bezerra de Lima; Marcos Romualdo Barbosa; Regina Sheila \\ Barros dos Anjos; Rafaela Duarte Borges; José Galdino Cavalcante Neto; Luciano Façanha Marques \\ UFERSA, C.Postal 137, 59625-900, Mossoró-RN; damianacm@hotmail.com; lucifm@hotmail.com; galdinoneto@hotmail.com
}

\section{RESUMO}

Com o objetivo de avaliar o desenvolvimento de mudas de alface que foram desenvolvidas em diferentes substratos e sob efeito de adubação foliar usando biofertilizantes, foi realizado o experimento em casa de vegetação da UFERSA. Utilizou-se o delineamento de blocos ao acaso com 4 repetições. Os tratamentos foram resultados de um fatorial 4 x 5 envolvendo tipos de substrato (composto orgânico, Gold Mix 11, areia lavada e húmus + areia lavada 1:1) e fertilizante foliar (organo-mineral comercial Fertamin, testemunha e três tipos de biofertilizantes). Foram feitas adubações foliares nas mudas, aos oito e aos 15 dias após a semeadura. O fertilizante organo-mineral comercial Fertamin apresentou os melhores resultados para massa seca da parte aérea, massa seca da raiz e número de folhas. Dentre os biofertilizantes, aquele à base de esterco de curral fresco, cinzas, leite e caldo de cana apresentou os menores valores para essas mesmas características avaliadas. O composto orgânico foi o que apresentou os maiores valores para todas as características avaliadas, exceto para comprimento da raiz.

Palavras-chaves: Lactuca sativa L., adubação foliar, matéria seca.

\begin{abstract}
Production of lettuce plantlets using biofertilizer and substrates

The development of lettuce plantlets was evaluated, employing different substrate types and applying foliar biofertilization. The research was done in a green house in Mossoró, Rio Grande do Norte State, Brazil. The experimental design was of randomized blocks with four replications. The treatments were composed of the interaction substract type (composed organic, Golden Mix 11, washed sand and humus + washed sand 1:1) and fertilizer (the commercial organo-mineral Fertamin, the witness and tree biofertilizer types). Plantlets were foliar fertilized 8 and 15 days after sowing date. Plantlets treated with Fertamim presented the best results in the dry matter of the aerial part, dry matter of roots and number of leaves. Among the biofertilizers, the one based on cattle manure, leached ash, milk and broth of sugar cane presented the lesser values for the same evaluated characteristics. The organic substract presented the highest values for all the appraised characteristics, except for root length.
\end{abstract}

Keywords: Lactuca sativa L., foliar fertilization, dry matter.

(Recebido para publicação em 20 de abril de 2006; aceito em 8 de agosto de 2007)

\begin{abstract}
A alface (Lactuca sativa L.) é uma das hortaliças mais cultivadas em todo o país. A sua larga adaptação às condições climáticas diversas, a possibilidade de cultivos sucessivos no mesmo ano, o baixo custo de produção, a pouca suscetibilidade a pragas e doenças e a comercialização segura, fazem com que seja a hortaliça preferida pelos pequenos produtores, o que lhe confere grande importância econômica e social, sendo significativo fator de agregação do homem do campo.

Para se obter produtos com ótimo estado para comercialização, é muito importante obter mudas sadias e vigorosas. A produção em larga escala de mudas de alta qualidade tem motivado os produtores a adotarem técnicas e metodologias mais modernas, procurando obter mudas uniformes e que atendam às suas necessidades. A produção e transplante de mudas é uma prática muito uti-
\end{abstract}

lizada no cultivo das hortaliças, particularmente daquelas com sementes muito pequenas. A utilização de mudas permite maior controle do espaçamento, garante a população desejada, plantas uniformes e facilita o controle de ervas daninhas (Fontes, 2005).

O emprego de fertilizantes e defensivos químicos em hortaliças é uma prática agrícola que traz resultados satisfatórios, porém deve-se levar em consideração a qualidade do produto, pois sabe-se que o uso desordenado desses produtos pode vir a prejudicar a saúde dos consumidores, além de onerar o custo de produção (Costa, 1994).

A importância da adubação foliar está na suplementação da adubação no solo e na correção mais rápida de deficiências eventuais ou sistemáticas (Malavolta \& Romero, 1975). A aplicação de fertilizantes foliares está sendo cada vez mais utilizada pelos produto- res. Uma das alternativas que vem sendo usada por muitos agricultores é a aplicação de efluente, estercos de animais, materiais vegetais e sais minerais; pela transformação aeróbica ou anaeróbica, esse produto final é conhecido como organomineral ou biofertilizante (Kiehl, 1993).

O uso de produtos alternativos como os biofertilizantes vem crescendo em todo o Brasil. Na busca por insumos menos agressivos ao ambiente e que possibilitem o desenvolvimento de uma agricultura menos dependente de produtos industrializados, vários produtos têm sido lançados no mercado (Deleito, et al. 2000). Além disso, esses produtos podem ser produzidos pelo próprio agricultor, gerando economia de insumos importados e, ainda, promovendo melhorias no saneamento ambiental. Os biofertilizantes são fáceis de fazer, uma vez que geralmente são compostos de 
DC Medeiros et al.

Tabela 1. Resultados da análise química dos substratos utilizados no experimento (Results of the chemical analysis of the substrata utilized in this research). Mossoró, UFERSA, 2005.

\begin{tabular}{|c|c|c|c|c|c|c|c|c|c|c|}
\hline \multirow{2}{*}{ Amostra } & \multirow{2}{*}{$\mathrm{pH}$} & $\mathrm{Al} 3+$ & $\mathrm{Ca}+\mathrm{Mg}$ & $\mathrm{Ca} 2+$ & Mg2+ & $\mathrm{Na}+$ & $\mathbf{K}$ & \multirow{2}{*}{$\begin{array}{c}P \\
\left(\mathrm{mg} \mathrm{dm}^{-3}\right)\end{array}$} & \multirow{2}{*}{$\begin{array}{c}\mathrm{C} \\
\left(\mathrm{g} \mathrm{kg}^{-1}\right)\end{array}$} & \multirow{2}{*}{$\begin{array}{c}\text { MO } \\
\left(\mathrm{g} \mathrm{kg}^{-1}\right)\end{array}$} \\
\hline & & \multicolumn{6}{|c|}{$\left(\right.$ cmolc $\left.\mathrm{dm}^{-3}\right)$} & & & \\
\hline Composto orgânico & 7,50 & 0,00 & 18,50 & 13,4 & 5,10 & 0,35 & 3,17 & 447,40 & 36,70 & 63,28 \\
\hline Gold Mix 11 & 6,20 & 0,00 & 6,80 & 5,5 & 1,30 & 0,33 & 3,66 & 172,12 & 247,00 & 426,15 \\
\hline Areia Lavada & 8,20 & 0,00 & 4,00 & 3,5 & 0,50 & 0,23 & 0,13 & 78,41 & 2,62 & 4,52 \\
\hline Húmus+ Areia (1:1) & 6,90 & 0,00 & 14,30 & 6,6 & 7,70 & 0,84 & 2,11 & 447,40 & 25,47 & 43,91 \\
\hline
\end{tabular}

Tabela 2. Resultados da análise química dos diferentes substratos utilizados no experimento (Results of the chemical analysis of the substrata utilized in this research). Mossoró, UFERSA, 2005.

\begin{tabular}{|c|c|c|c|c|c|}
\hline \multirow{2}{*}{ Amostra } & \multirow{2}{*}{$\mathrm{CE}(\mathrm{dS} / \mathrm{m})$} & \multirow{2}{*}{$\begin{array}{l}\mathrm{N} \text { total } \\
\mathrm{g} / \mathbf{k g}\end{array}$} & $\mathbf{H}$ & стC & \multirow{2}{*}{$\begin{array}{c}\text { Sat. bases } \\
(\%)\end{array}$} \\
\hline & & & \multicolumn{2}{|c|}{$\left(\right.$ cmolc dm ${ }^{-3}$ ) } & \\
\hline Composto orgânico & 0,72 & 7,25 & 2,31 & 24,33 & 90,5 \\
\hline Gold Mix 11 & 1,38 & 8,60 & 6,35 & 17,14 & 63,0 \\
\hline Areia Lavada & 0,08 & 0,30 & 0,33 & 4,69 & 93,0 \\
\hline Húmus + Areia (1:1) & 0,90 & 3,01 & 4,70 & 21,95 & 78,6 \\
\hline
\end{tabular}

excrementos de animais, encontrados sem muita dificuldade. Esses biofertilizantes são preparados a partir da digestão anaeróbica ou aeróbica de material orgânico e mineral, visando o fornecimento de nutrientes.

Para Bettiol, et al, (1998), uma das principais características do biofertilizante é a presença de microorganismos, responsáveis pela decomposição da matéria orgânica, produção de gás e liberação de metabólitos, especialmente antibióticos e hormônios.

Aliado à qualidade das mudas, o produtor de hortaliças constantemente sente a necessidade de reduzir os custos de sua atividade. Para tanto, trabalhos são realizados com a finalidade de aproveitar material disponível regionalmente, para compor o substrato para a formação de mudas de hortaliças, em diminuição da participação de substratos comerciais, os quais invariavelmente, apresentam-se desuniformes, principalmente quanto à natureza química, traduzida por ocorrências de distúrbios nutricionais nas plântulas (Silva et al., 2000).

O substrato deve apresentar características físicas, químicas e biológicas apropriadas que permitam pleno crescimento das raízes e da parte aérea (Setubal \& Afonso Neto, 2000). A produção da muda em substrato esterilizado é outra vantagem importante, pois é levada para o campo isenta de nematóides e outros fitopatógenos, que poderiam contaminá-la numa sementeira em canteiro (Caetano et al., 2001).

Câmara (2001), ao avaliar compostos orgânicos como substrato na produção de mudas de alface, verificou que o composto orgânico misto pode substituir com sucesso os substratos comerciais, sendo economicamente viável.

O objetivo do presente trabalho foi avaliar o desenvolvimento de mudas de alface em diferentes tipos de substratos e sob efeito de adubação foliar usando biofertilizantes.

\section{MATERIAL E MÉTODOS}

O experimento foi realizado na horta da UFERSA com 187,5 m² e 50\% de área sombreada. O delineamento experimental utilizado foi de blocos casualizados em esquema fatorial $4 \times 5$, com quatro repetições. Os tratamentos resultaram da combinação dos fatores tipos de substratos, Foram utilizados composto orgânico; Gold Mix 11; areia lavada; e húmus + areia lavada (1:1). Para o fator tipos de fertilizantes foliares foram utilizados: sem fertilizante ou testemunha; fertilizante organo-mineral comercial Fertamin; biofertilizante 1; biofertilizante 2 e biofertilizante 3 . Cada parcela foi constituída de 32 células. Utilizou-se a cultivar 'Maravilha de Verão'.
Os biofertilizantes usados para a adubação foliar foram feitos com as seguintes formulações: Biofertilizante 1: $1 \mathrm{~kg}$ de diferentes folhas picadas, 0,3 L de leite, 0,5 L de caldo de cana, 0,2 kg de cinzas, $0,1 \mathrm{~kg}$ de farinha de osso, 0,1 kg de calcário dolomítico. No $1^{\circ}$ dia colocou-se as folhas de molho em $2 \mathrm{~L}$ de água e acrescentou-se 0,15 L de leite, $0,25 \mathrm{~L}$ de caldo de cana, 0,1 kg de cinzas e $2 \mathrm{~kg}$ de farinha de osso, mexeu-se bem e deixou-se fermentar. No $7^{\circ}$ dia adicionou-se $0,15 \mathrm{~L}$ de leite, 0,25 $\mathrm{L}$ de caldo de cana, $0,1 \mathrm{~kg}$ de cinzas, 0,1 kg de calcário dolomítico e completouse o volume para $5 \mathrm{~L}$. Biofertilizante 2: $1 \mathrm{~kg}$ de esterco de curral fresco, 0,25 kg de esterco de galinha fresco, $1 \mathrm{~L}$ de diferentes folhas verdes (picadas), 0,25 L de leite, 0,45 L de caldo de cana, 0,25 $\mathrm{kg}$ de cinzas, 0,1 kg de farinha de osso, 1 kg de calcário dolomítico, completouse o volume de $5 \mathrm{~L}$ com água e mexeuse bem. Biofertilizante 3: 1,25 kg de esterco de curral fresco, $0,125 \mathrm{~kg}$ de cinzas, 0,1 L de leite, 0,2 L de caldo de cana. No $1^{\circ}$ dia misturou-se $1,25 \mathrm{~kg}$ de esterco, 2,5 L de água, 0,05 L de leite, 0,1 L de caldo de cana e $0,0625 \mathrm{~kg}$ de cinzas. Quatro dias depois, em um outro recipiente, dissolveu-se $0,0625 \mathrm{~kg}$ de cinzas em 0,05 L de leite e acrescentou-se a outra mistura e completou-se o volume com água.

Antes de instalar o experimento, os substratos foram peneirados e submetidos ao tratamento com água quente a $100^{\circ} \mathrm{C}$ (exceto o Gold Mix 11), com a finalidade de estereliza-los, e após dois dias preencheu-se as bandejas de 128 células, semeando a alface logo em seguida. Dez dias apoós a semeadura, foi feito o desbaste deixando uma planta por célula. As análises foram feitas aos 21 dias da semeadura.

As irrigações foram realizadas com regador duas vezes ao dia. Foram feitas 
Tabela 3. Resultados da análise dos fertilizantes utilizados no experimento (Results of the chemical analysis of the substrata utilized in this research). Mossoró, UFERSA, 2005.

\begin{tabular}{|c|c|c|c|c|c|c|c|c|c|c|c|c|}
\hline \multirow[t]{2}{*}{ Amostras } & \multirow[t]{2}{*}{$\mathrm{PH}$} & \multirow{2}{*}{$\begin{array}{l}\text { C.E. } \\
\text { (dS/m) }\end{array}$} & $\mathrm{Ca}^{2+}$ & $\mathbf{M g}^{2}+$ & $\mathrm{K}+$ & $\mathrm{Na}+$ & $\mathrm{Cl}-$ & $\mathrm{HCO}^{3}-$ & CO32- & $\begin{array}{c}\text { S.D. } \\
\left(\mathrm{mg} / \mathrm{dm}^{3}\right)\end{array}$ & RAS & RASaj \\
\hline & & & \multicolumn{10}{|c|}{$\left(\mathrm{mmolc} / \mathrm{dm}^{3}\right)$} \\
\hline Biofertilizante 2 & 6,9 & 1,385 & 4,8 & 1,6 & 2,69 & 4,90 & 3,8 & 9,0 & 0,0 & 886 & 2,74 & 3,68 \\
\hline Biofertilizante 3 & 8,8 & 18,920 & 1,0 & 0,5 & 10,06 & 13,01 & 1,8 & 137,0 & 30,0 & 12109 & 15,02 & 33,65 \\
\hline Biofertilizante 4 & 8,2 & 1,260 & 1,8 & 1,0 & 0,68 & 4,57 & 3,0 & 5,8 & 0,0 & 806 & 3,86 & 6,41 \\
\hline Biofertilizante 5 & 7,2 & 0,936 & 1,6 & 1,8 & 0,80 & 4,99 & 2,8 & 6,6 & 0,0 & 599 & 3,82 & 6,32 \\
\hline
\end{tabular}

duas adubações foliares como diferentes fertilizantes (de acordo com o tratamento), a primeira aos oito dias e a segunda quinze dias após a semeadura. Para a aplicação dos fertilizantes utilizou-se um pequeno borrifador manual, e a concentração das soluções foram de 2,5\% de acordo com o rótulo do fertilizante comercial Fertamin.

As análises das amostras dos substratos e dos fertilizantes (Tabelas 1, 2 e 3) foram feitas no Laboratório de análises de solo da UFERSA de acordo com a metodologia de Silva et al. (1998).

Foram avaliados o comprimento de raiz e da parte aérea, matéria seca de raiz e matéria seca da parte aérea e número de folhas. Os dados obtidos foram submetidos à Análise de Variância (teste F) e os tratamentos comparados através do teste de Tukey, ao nível de 5\% de probabilidade pelo programa SISVAR UFLA.

\section{RESULTADOS E DISCUSSÃO}

Não houve efeito significativo na interação fertilizante e substrato nas variáveis estudadas. Porém houve efeito significativo para o biofertilizante apenas na matéria seca da raiz, matéria seca da parte aérea e para o número de folhas. Enquanto para os substratos, todas as características avaliadas apresentaram efeito significativo. Das características avaliadas, apenas o comprimento de raiz e altura de planta não apresentaram efeito significativo para fator biofertilizante (Tabela 4). O fertilizante organo-mineral comercial Fertamin apresentou os maiores valores para matéria seca de raiz, massa seca da parte aérea e do número de folhas. Os biofertilizantes 1 e 2 não diferiram da testemunha. Dentre os biofertilizantes, o
Tabela 4. Altura de plantas (AP), matéria seca da parte aérea (MSPA), número de folhas (NF), comprimento da raiz (CR) e matéria seca da raiz (MSR) de mudas de alface cultivadas em diferentes fertilizantes e substratos (Plant height (AP), dry matter of aerial part (MSPA), number of leaves (NF), root lenght (CR) and root dry matter (MSR) of lettuce plantlets cultivated in variour fertilizers and substrata). UFERSA, Mossoró, 2005.

\begin{tabular}{lcclccc}
\hline \multicolumn{7}{c}{ QM (características) } \\
\hline FV & GL & AP (cm) & MSPA (g) & NF & CR (cm) & MSR (g) \\
\hline Biofertilizante & 4 & $4,3449 n . s$. & $0,0018^{*}$ & $5,1124^{*}$ & $1,0021^{\text {n.s. }}$ & $0,0002^{*}$ \\
Substratos & 3 & $17,3027^{*}$ & $0,0129^{*}$ & $18,5628^{*}$ & $32,643^{*}$ & $0,0008^{*}$ \\
Biof. X Subst. & 12 & $1,3799^{\text {n.s. }}$ & $0,0003^{\text {n.s }}$ & $1,1137^{\text {n.s. }}$ & $1,8183^{\text {n.s. }}$ & $0,0001^{\text {n.s. }}$ \\
Erro & & 2,8502 & 0,0003 & 1,1995 & $2,0762^{2}$ & 0,0001 \\
Média & 3,96 & 0,0377 & 6,0510 & 7,2708 & 0,0135 \\
\hline CV $(\%)$ & 12,69 & 19,69 & 18,10 & 19,82 & 15,84 \\
\hline
\end{tabular}

*Significância a 5\% de probabilidade (*significative, 5\%).

Tabela 5. Valores médios de matéria seca da parte aérea (MSPA), matéria seca da raiz (MSR) e número de folhas (NF) de mudas de alface em função de diferentes fertilizantes (average values of dry matter of aerial part (MSPA), dry matter of roots (MSR) and number of leaves (NF) of lettuce plantlets as a result of various fertilizers). UFERSA, Mossoró, 2005.

\begin{tabular}{llll}
\hline Fertilizantes & MSPA & MSR & NF \\
\hline Fertamim & $0,052 \mathrm{a}$ & $0,018 \mathrm{a}$ & $6,83 \mathrm{a}$ \\
Biofertilizante 1 & $0,038 \mathrm{~b}$ & $0,013 \mathrm{~b}$ & $6,16 \mathrm{~b}$ \\
Biofertilizante 2 & $0,042 \mathrm{~b}$ & $0,015 \mathrm{~b}$ & $6,12 \mathrm{~b}$ \\
Biofertilizante 3 & $0,024 \mathrm{c}$ & $0,009 \mathrm{c}$ & $5,26 \mathrm{~b}$ \\
Testemunha & $0,039 \mathrm{~b}$ & $0,012 \mathrm{~b}$ & $5,89 \mathrm{~b}$ \\
\hline
\end{tabular}

Médias seguidas pelas mesmas letras, nas colunas, não diferem estatisticamente, entre si, pelo Teste de Tukey, a 5\% de probabilidade (average values followed from the same letter in the column did not differ from each other, Tukey, 5\%).

Tabela 6. Valores médios de altura de planta (AP), número de folhas (NF), matéria seca da raiz (MSR), matéria seca da parte aérea (MSPA) e comprimento de raiz (CR) de mudas de alface em função de diferentes substratos (average values for plant height (AP), number of leaves (NF), dry matter of roots (MSR), dry matter of aerial part (MSPA) and root lenght (CR) of lettuce plantlets depending on variours substrata). UFERSA, Mossoró, 2005.

\begin{tabular}{lccccc}
\hline Substratos & AP & NF & CR & MSPA & MSR \\
\hline Composto orgânico & $5,26 \mathrm{a}$ & $7,25 \mathrm{a}$ & $6,82 \mathrm{c}$ & $0,072 \mathrm{a}$ & $0,022 \mathrm{a}$ \\
Húmus + areia lavada (1:1) & $4,02 \mathrm{~b}$ & $6,41 \mathrm{a}$ & $5,73 \mathrm{~d}$ & $0,042 \mathrm{~b}$ & $0,012 \mathrm{~b}$ \\
Gold Mix 11 & $3,39 \mathrm{c}$ & $5,27 \mathrm{~b}$ & $8,68 \mathrm{a}$ & $0,021 \mathrm{c}$ & $0,011 \mathrm{~b}$ \\
Areia lavada & $3,19 \mathrm{c}$ & $5,27 \mathrm{~b}$ & $7,85 \mathrm{~b}$ & $0,016 \mathrm{c}$ & $0,009 \mathrm{~b}$ \\
\hline
\end{tabular}

Médias seguidas pelas mesmas letras, nas colunas, não diferem estatisticamente, entre si, pelo Teste de Tukey, a 5\% de probabilidade (average values followed from the same letter in the column did not differ from each other, Tukey, 5\%). 
número 3 foi o que apresentou estatisticamente os menores valores (Tabela 5). Os biofertilizantes 1 e 2 foram os que receberam maiores doses de minerais, recebendo, além de cinzas, calcário dolomítico e farinha de osso, enquanto que o biofertilizante 3 só recebeu cinzas.

Avaliando o crescimento de alface cultivada com uma solução nutritiva de origem mineral e três de origem orgânica, Menezes Júnior (2004) constatou que a solução mineral foi aquela que proporcionou o maior crescimento vegetal e que os biofertilizantes que receberam adição de micronutrientes resultaram nos maiores crescimento de mudas de alface.

Para o substrato houve efeito significativo em todas as características estudadas. Para a altura da parte aérea o substrato composto orgânico foi que apresentou maior valor. Para a característica número de folhas o composto orgânico e húmus + areia lavada apresentaram os maiores valores em relação aos demais substratos. O Gold Mix 11 apresentou o melhor efeito para a característica comprimento da raiz. Para a massa seca da parte aérea e massa seca da raiz o composto orgânico proporcionou os maiores valores.

Câmara (2001), estudando diferentes compostos orgânicos na produção de mudas de alface, constatou que os substratos composto misto e composto de folhas de cajueiro foram superiores ao substrato comercial Plantmax, em todas as características avaliadas. Brito et al. (2002), avaliando o desempenho de substratos em agricultura orgânica, verificaram que alguns substratos à base de vermicomposto podem ser usados em substituição aos substratos comerciais quando o objetivo é a produção de mudas de alface. Resultados semelhantes ao deste trabalho de pesquisa.

Avaliando a produção de mudas de tomateiro utilizando húmus de minho- ca e cama de aviário como substrato e o biofertilizante Agrobio como adubação foliar em diferentes concentrações, Souza et al. (2002) observaram que não houve efeito da variável biofertilizantes e da interação entre os tipos de substratos e as concentrações de biofertilizantes, mas observaram diferença significativa para a variável substrato, no qual o substrato composto de húmus de minhoca enriquecido com 5\% de cama de aviário apresentou melhores resultados, quando comparado com o substrato comercial Plantmax.

O fertilizante organo-mineral comercial Fertamin apresentou os melhores resultados para massa seca da parte aérea, massa seca da raiz e número de folhas e dentre os biofertilizantes, aquele à base de esterco de curral fresco, cinzas, leite e caldo de cana apresentou os menores valores para essas mesmas características avaliadas.

O composto orgânico foi o que apresentou os maiores valores para todas as características avaliadas, exceto para comprimento da raiz.

O bom desempenho alcançado pelas plantas submetidas aos tratamentos de origem orgânica evidencia a possibilidade de produção de mudas de alface em soluções aeróbicas produzidas facilmente pelo produtor.

\section{REFERÊNCIAS}

BETTIOL W; TRATCH R; GALVÃO JAH. ' 998. Controle de doenças de plantas com biofertilizantes. Jaguariúna, SP: EMBRAPA CNPMA, 22p. (Circular técnico, 02).

BRITO TD; RODRIGUES CDS; MACHADO CA. 2002. Avaliação do desempenho de substratos para produção de mudas de alface em agricultura orgânica. In: $42^{\circ}$ Congresso brasileiro de Olericultura, Horticultura Brasileira 202002.

CAETANO LCS. 2001. A cultura da alface: perspectivas, tecnologias e viabilidade. Niterói RJ: PESAGRO-RIO, 23 p. (PESAGRO-RIO. Documentos, 78).
CÂMARA MJT. 2001. Diferentes compostos orgânicos e Plantmax como substratos na produção de mudas de alface, Mossoró-RN: ESAM, 32 p. (Monografia graduação).

COSTA CA. 1994. Crescimento e teores de sódio e de metais pesados da alface e da cenoura adubada com compostos orgânicos de lixo urbano. Viçosa, MG. UFV, 89 p. (Tese mestrado).

DELEITO CSR; CARMO GF; ABBOUND ACS; FERNANDES MCA. 2000. Sucessão microbiana durante o processo de fabricação do biofertilizante Agrobio. In: FERTBIO 2000. Santa Maria, RS: Sociedade Brasileira de Ciências do Solo e da Sociedade Brasileira de Microbiologia, CD-ROM.

FONTES PCR. 2005. Olericultura: teoria e prática, Viçosa-MG: UFV, 486p.

KIEHL EJ. 1993. Fertilizantes organominerais. Piracicaba: Agronômica Ceres, 189p.

MALAVOLTA E; ROMERO JP. 1975. Manual de adubação. 2 ed. São Paulo-SP: ANDA, p.193200.

MENEZES JÚNIOR FOG; MARTINS SR; FERNANDES HS. 2004. Crescimento e avaliação nutricional da alface cultivada em "NFT" com soluções nutritivas de origem química e orgânica. Horticultura Brasileira 22: 632-637.

SILVA FC; EIRA PA; BARRETO WO; PEREZ DV; SILVACA. 1998. Análises químicas para avaliação da fertilidade do solo: método usados na EMBRAPA SOLOS. EMBRAPA/ Centro Nacional de Pesquisa de Solos.

SETUBAL JW; AFONSO NETO FC. 2000. Efeito de substratos alternativos e tipos de bandejas na produção de mudas de pimentão. Horticultura Brasileira 18: 593-594.

SILVAACR; FERNANDES HS; MARTINS SR; SILVA JB; SCHIEDECK G; ARMAS E. 2000. Produção de mudas de alface com vermicompostos em diferentes tipos de bandeja. In: $40^{\circ}$ Congresso Brasileiro de Olericultura, Horticultura Brasileira 18: 512523.

SOUZA JMPF; LEAL MA; ARAÚJO ML. 2002. Produção de mudas de tomateiro utilizando húmus de minhoca e cama de aviário como substrato e o biofertilizante Agrobio como adubação foliar, Seropédica-RJ: PESAGRO RIO. 